УДК 654.071:.001:621.9.022:004.4

A. M. Silvestrov, A. I. Sorokovyi, A. I. Laktionov

\title{
TRAINING OF NUMERICAL CONTROL MACHINES OPERATORS: MODEL OF SYNTHESIS
}

Abstract. In the article considered topical problems of developing an automated system, designed for assessing the competence level of industrial enterprises departments to fulfill their assignments as intended, as well as for planning activities on training experts in technological processes automation.

Key words. model synthesis, competence, technical specialists, knowledge control, automated mechanisms, machines, computer numerical control.

Introduction and the problem statement. Today, on the territory of modern Ukraine, assessment of the experts' competence level is, in most cases, performed in a no automated way, and the assessment results are stored within the divisions of an enterprise. In view of it, there is no possibility to efficiently plan the activities of training experts of technological processes automation and relevant units, as well as individual numerical control machines operators (Borodin, Andreyev, 2006).

It is on this particular basis, there is a possibility to substantiate the topicality of developing an automated system, designed for assessing the competence level of industrial enterprises departments to fulfill their assignments as intended, as well as for planning activities on training experts in technological processes automation.

Training experts in technological processes automation includes a set of measures for organizing and solving the tasks of industrial enterprises functioning. Let's define that taking into account systemic consistency and features of the running the events, as well as the competence level index calculation, through the example of the numerical control machine operators, will permit the efficiency of training .

The present organization of the decision making process concerning training has the following disadvantages:

- changes in the training activities content are not provided, the syllabus is drawn up under the template, training syllabi of various technological divisions only differ in terms of specific training activities;

(C) A. M. Silvestrov, A. I. Sorokovyi, A. I. Laktionov 
- heads of the respective levels may only, to some extent, change the dates of the training activities carried out according to their syllabi;

- the achieved level of an expert's competence is not taken into account.

The decision is based solely on heuristic abilities and knowledge of the chiefs and their deputies. There is no scientifically grounded information base, which could be the reason for decision made by the chief of the appropriate level. Taking into consideration the existing disadvantages, it is suggested to adapt the process of planning activities on training the experts in technological processes automation to changes of assignments and to the handling competence level. To achieve that, it is necessary to create a model of synthesizing the plan of training numerical control machine operators.

Aim of the study. To explain the synthesis model of numerical control machine operators training. To present the general model of adaptive planning of training experts on technological processes automation. To interpret the theoretical and conceptual framework in terms of planning tasks for training experts in technological processes automation. To develop a planning process for training numerical control machine operators within the parameters of the activities being run.

Latest research and publications analysis. Within the frame of research developments study, concerning the process of the competence assessment of engineering experts automation, the high level of the contemporary researchers' achievements should be mentioned.

The automatized approach is disclosed by such outstanding scientists as O. G. Berestnieva, Ye. A. Muratova (Berestnyeva, Muratova, 2010) and O. V. Marukhin, G. Ye. Shevelyov (Marukhin, Shevelyov, 2009).

It had been O. G. Berestnieva, Ye. A. Muratova (Berestnyeva, Muratova, 2010), who defined the basic fields of studying the engineering expert's competence.

Authors, such as V. M. Vdovin, L. E. Surkova, V. A. Valentynov (Vdovin, Surkova, Valentinov, 2013) present exhaustive information on the information matrices compiling and on the systemic analysis methodology within the frame of the studied system.

Concerning the systemic analysis within the assignment of duties, an important role has been played by the work of V. I. Kyrylov, while the present study was being written. 
The aspects of documentation processes automation are described by E. E. Boyko (Boyko, 2010). In his paper, E. E. Boyko approaches to records management structuring and to the mechanisms of providing the routine processes automation.

However, irrespective of the large scale scientific research on the engineering experts' competence assessment, the problem of assessment scales and the principles alignment is remaining open up to now.

Main research material statement. Relying on the essence of the adaptive planning, i.e. to combine the advantages of reasoning with the necessity of providing flexibility in training and in the training process organizing, it (adaptive planning) includes the following stages:

1) preparing the initial data, needed for planning;

2) training plan (syllabus) compiling;

3) modeling the training process, taking into account the information model of training activities interaction;

4) defining the qualification level as an integral index of the obtained knowledge, abilities and habits (KAH).

Fig. 1 presents a general model of the adaptive planning for the technological processes automation experts' training.

By reference to the assignments on organizing and to peculiarities of training technological processes automation experts, training is planned for the period, which length is defined by the training time $\mathrm{T}_{\mathrm{t}}$ and by the number of facilities $-\mathrm{S}_{\mathrm{f}}$, furnished for training.

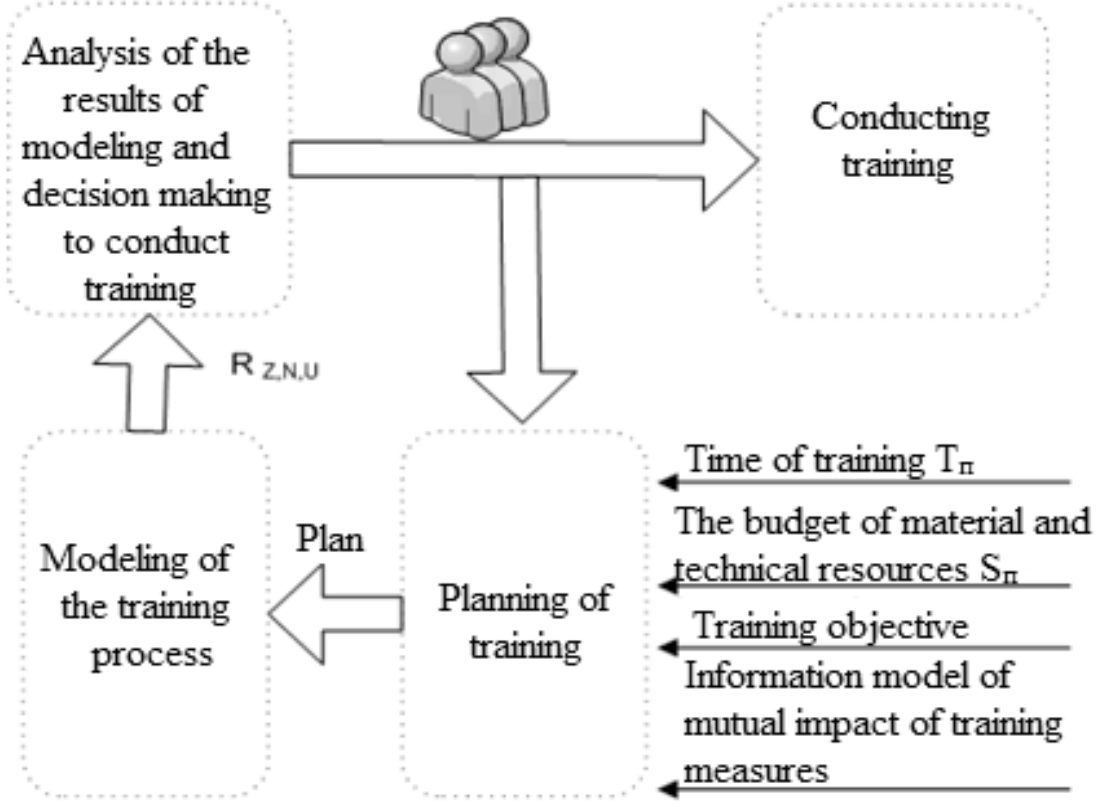

Fig. 1. General model for the adaptive planning of technological processes automation experts' training 
The process of training technological processes automation experts must provide raising the competence level of the numerical control machine operators for the whole period of its delivery. Therefore, the general training level $-R^{t}-$ must fall within the range of:

$$
R_{\min }^{\Pi} \leq R^{\Pi} \leq R_{\max }^{\Pi} \cdot
$$

During the $T_{t}$ period, various training activities are performed, for example: classes, teaching, training, etc. A training activity consists of modules, aimed at formation of the appropriate $\mathrm{KAH}$ level.

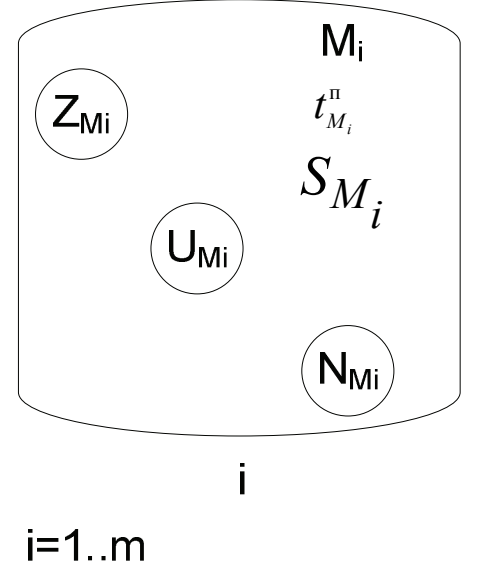

Fig. 2. Structural model of training activity $M_{i}$

Every activity $M_{i}$ is located in the multitude:

$$
M_{i} \in\{M\}, i=\overline{1, m},
$$

where $\{M\}$ is a set of all training measures available to be conducted

Each separate training activity $M_{i}$ is characterized by the knowledge gain $Z_{M_{i}} \in Z, i=\overline{1, m}$, abilities $-U_{M_{i}} \in U, i=\overline{1, m}$, habits $N_{M_{i}} \in N, i=\overline{1, m}$, by the time of delivery $t_{M_{i}}^{\mathrm{I}}$ and the integrated cost of material and technical facilities $S_{m i}$ necessary for its delivery

The training quality level $R_{M_{i}}^{\Pi}$, as a totality of $\mathrm{KAH}$, formed by the activity $M_{i}$ in the process of training, is calculated according to the formula:

$$
R_{M_{i}}^{\Pi}=f\left(Z_{M_{i}}, N_{M_{i}}, U_{M_{i}}\right) \text {. }
$$

Relying on the activity's structure and on its direction, KAH quality levels $-Z_{M_{i}}, N_{M_{i}}, U_{M_{i}}$ for each training activity $M_{i}$ and function $f$ are defined by the expert assessment method (Marukhin, Shevelyov, 2009). 
Each training activity $M_{i}$ is forming an information base with a certain index $K$ (for every $\mathrm{KAH}$ component respectively $K_{Z_{M_{i}}}, K_{U_{M_{i}}}$, $K_{N_{M_{i}}}$ ) for performing other training activities.

Thus, the KAH quality level $Z_{M_{i}}, N_{M_{i}}, U_{M_{i}}$ being formed for each of the training activities $M_{i}$ depends upon other, directly preceding, preparation training activities and, in its turn, influences the level of $\mathrm{KAH}$ being formed $-Z_{M_{i}}, N_{M_{i}}, U_{M_{i}}$ - by the following training activities.

Let us mark KAH levels being formed, taking into account the information base, created after performing other activities, directly preceding to the activity $M_{i}$, out of the infinite aggregate of all available for performing activities $M$ as $Z_{M_{i} / M}, N_{M_{i} / M}, U_{M_{i} / M}$ and the quality training level, thus formed, let us mark as $R_{M_{i} / M}^{\Pi}$.

Then, the formula (3) will be the following:

$$
R_{M_{i} / M}^{\Pi}=f\left(Z_{M_{i} / M}, N_{M_{i} / M}, U_{M_{i} / M}\right) .
$$

To account the considered connections of the $M_{i}$ activities on numeric control machines operators training, we should build an adjacency matrix of the mutual influence indexes $K \in[0 ; 1]$ for each component $Z, N, U$ of the mutual influence indexes $K_{Z_{M_{i}}}, K_{N_{M_{i}}}, K_{U_{M_{i}}}$ of the $M_{i}$ training elements

Adjacency matrices of indexes $K$ are compiled according to the list of activities. Each of them is a square matrix with the dimension equaling $\mathrm{m} \Psi \mathrm{m}$, i.e. to the number of training activities in the unit, lines and colons corresponding to the elements of $\mathrm{K} \mathrm{A} \mathrm{H}$ components.

Matrices elements are calculated according to the formula:

$$
K_{Z, U, N} i j= \begin{cases}K_{Z, U, N}, & \text { if the measurej forms information } \\ 0 & \text { base for i training measure } \\ \text { otherwise }\end{cases}
$$

In case, when $j$ activity is forming the information base for $i$ training activity, but it was not performed, then in the further calculations $K_{Z} i j$ is taken as equal to 0 . 
Thus, taking into account the adjacency matrices of the mutual influence indexes, the gain of $\mathrm{KAH}$, formed by each training activity $M_{i}$, taking into account the information base, obtained from the multitude $M$ of the earlier performed activities on training numeric control machines operators, can be written as:

$$
Z_{M_{i} / M}=Z_{M_{i}}+\sum_{j=1}^{m} Z_{M_{j}} \cdot K_{Z_{M_{j}}},
$$

Adjacency matrices of $\mathrm{K}$ indexes are presented in Fig. 3.

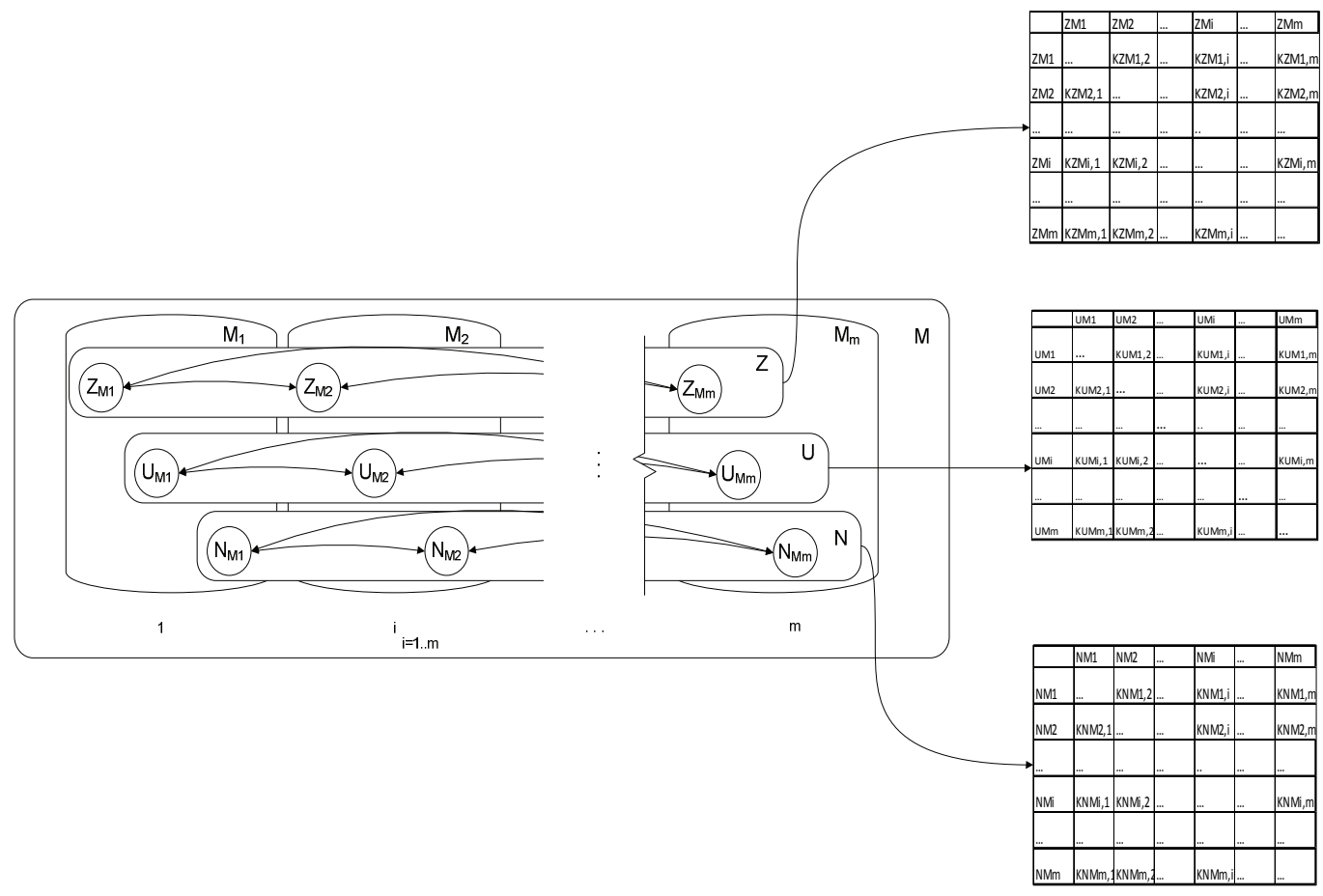

Fig. 3. Adjacency matrices of $K$ indexes of mutual influence $K_{Z_{M_{i}}}, K_{U_{M_{i}}}, K_{\mathrm{N}_{M_{i}}}$ components $Z, N, U$ of training measures

$$
\begin{aligned}
& U_{M_{i} / M}=U_{M_{i}}+\sum_{j=1}^{m} U_{M_{j}} \cdot K_{U_{M_{j}}}, \\
& N_{M_{i} / M}=N_{M_{i}}+\sum_{j=1}^{m} N_{M_{j}} \cdot K_{N_{M_{j}}} .
\end{aligned}
$$

Taking into account equations $6-8$, formula 3 will be as follows:

$$
R_{M_{i} / M}^{\Pi}=f\left(Z_{M_{i}}+\sum_{j=1}^{m} Z_{M_{j}} \cdot K_{Z_{M_{j}}}, U_{M_{i}}+\sum_{j=1}^{m} U_{M_{j}} \cdot K_{U_{M_{j}}}, N_{M_{i}}+\sum_{j=1}^{m} N_{M_{j}} \cdot K_{N_{M_{j}}}\right)
$$

The process of forming the quality level of training numeric control machines operators $R_{M_{i} / M}^{\Pi}$ is illustrated in Fig. 4. 


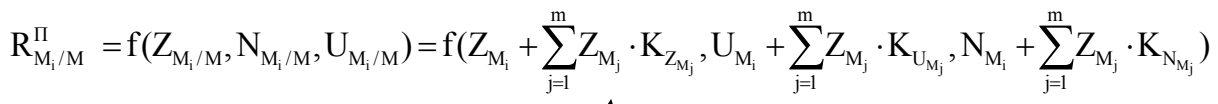
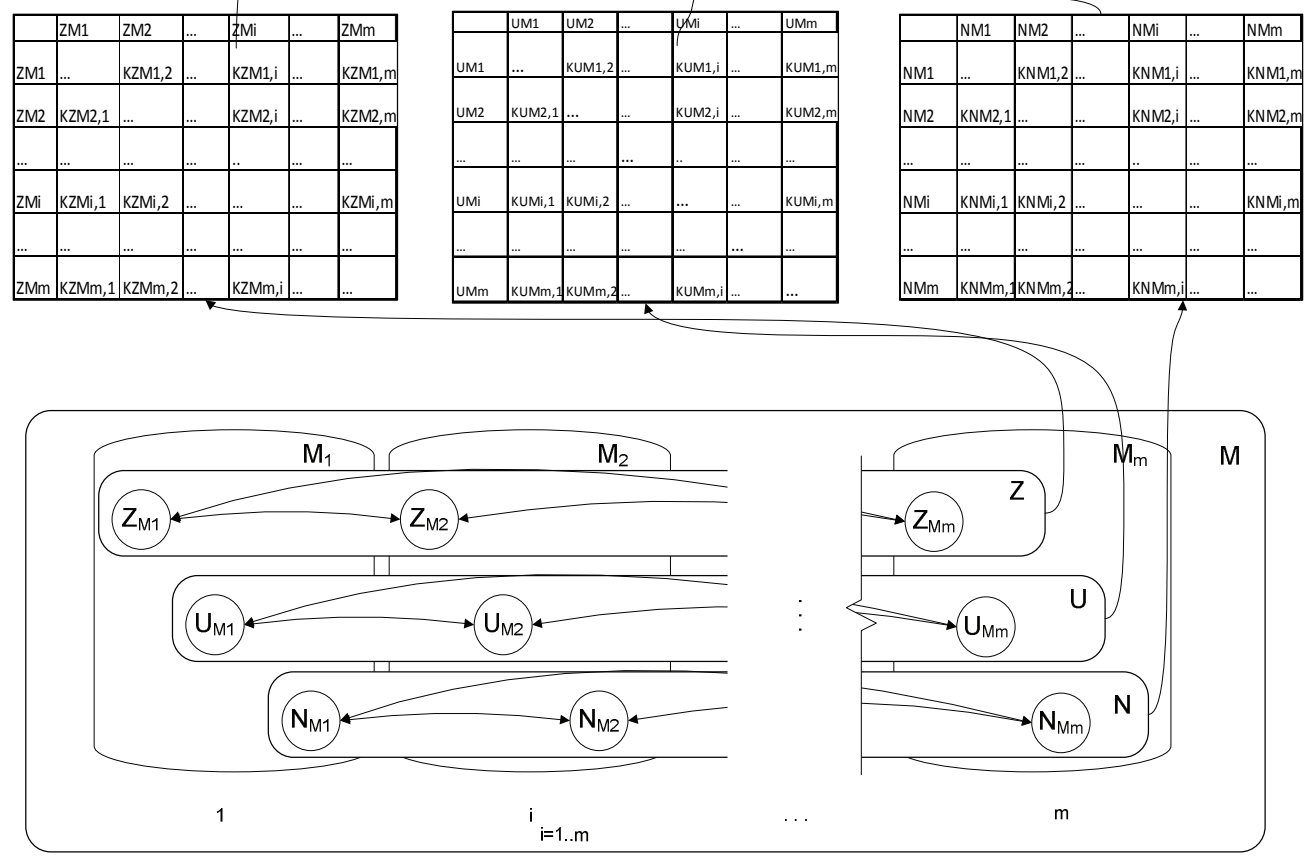

Fig. 4. Process of forming quality level $R_{M_{i} / M}^{\Pi}$, taking into account the information base, obtained from the training plan's multitude $M$ of the earlier performed activities on training numeric control machines operators

Using equations 6 - 9 we can define the level of training numeric control machines operators taking into account the information base, obtained from the earlier performed training activities of the multitude $M$ for any activity $M_{i}$ while planning training (Vdovin, Surkova, Valentinov, 2013).

In practice, while compiling the plan of numeric control machines operators training, ignoring the model describing the process of the training quality level formation and its losses, situations can arise, when the quality level of training the technological processes experts $R^{\Pi}$ is decreasing lower than the minimal level $R_{\min }^{\Pi}$, which means in- 
ability of experts and industrial enterprises divisions to fulfill their functional assignments.

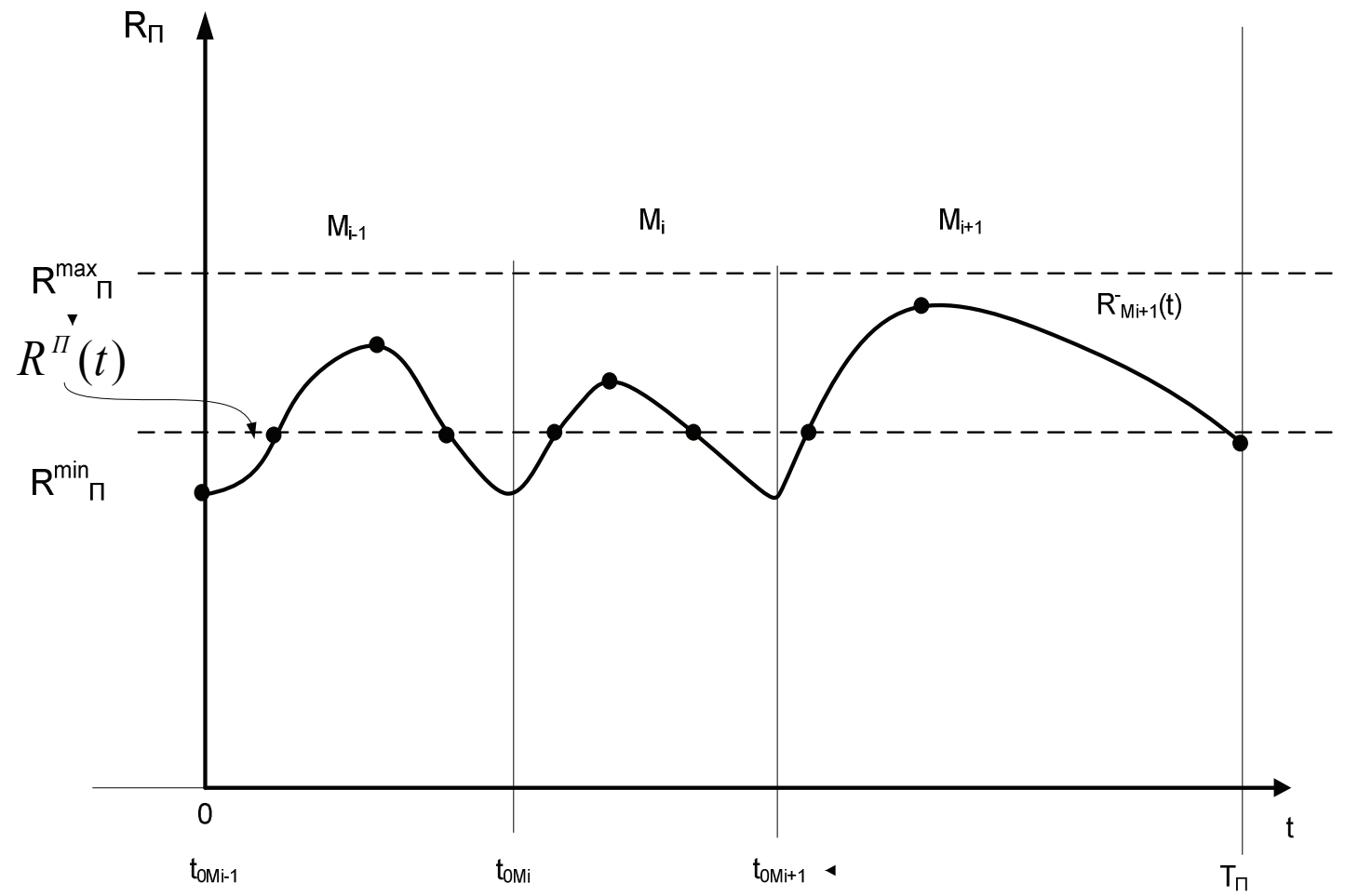

Fig. 5. Range of changes in the quality level of training the industrial enterprises divisions $R^{\Pi}$

The KAH levels are defined on the basis of using the suggested model of $\mathrm{KAH}$ formation, normally depending upon the time of training: according to the model of accumulation and losses of information in numeric control machines operators.

Let us interpret the theoretic and conceptual framework in terms of the assignment of planning the technological process automation experts training. Each activity $M_{i}$ in the training syllabus is characterized by the starting moment $t_{M_{i}}^{0}$ and the length of the training activity, i. e. time period $t_{M_{i}}^{\Pi}$. After performing the activity, the training quality level increases by the value $R_{M_{i}}^{\Pi}$ for the period of $t=t_{M_{i}}^{0}+t_{M_{i}}^{\Pi}$. The process of the training quality level increase $R_{M_{i}}^{\Pi}$ is described by the function $R_{M_{i}}^{\Pi+}$. After performing the training activity $M_{i}$, the training quality level of the technological processes automation experts $R_{M_{i}}^{\Pi}$ begins decreasing, which is described by the function of losses $R_{M_{i}}^{\Pi-}$. 


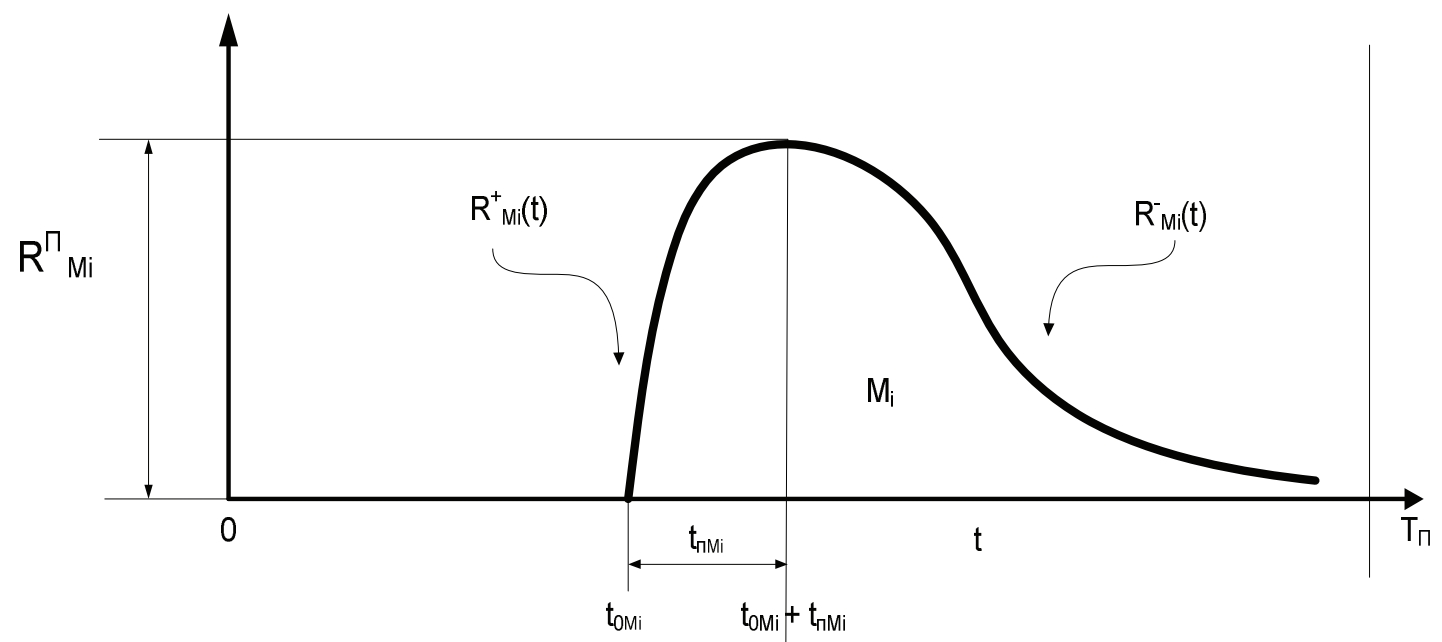

Fig. 6. Training quality level $R_{M_{i}}^{\Pi}$ formed at performing the activity $M_{i}$ as a function of time

We obtain the following equation to define the $R_{M_{i}}^{\Pi}$ level, depending on $t$ :

$$
R_{M_{I}}^{\Pi}(t)=\left\{\begin{array}{cc}
0, & t=t_{M_{i}}^{0} \\
R_{M_{I}}^{\Pi+}, & \text { if } t_{M_{i}}^{0}<t \leq\left(t_{M_{i}}^{0}+t_{M_{i}}^{\Pi}\right) \\
R_{M_{I}}^{\Pi-}, & \text { if } t>\left(t_{M_{i}}^{0}+t_{M_{i}}^{\Pi}\right)
\end{array} .\right.
$$

That is, while performing $M_{i}$ training activity, the training quality level $R^{\Pi}$ is increasing in the course of time $t=t_{M_{i}}^{0}$ according to the function of the knowledge gain $R_{M_{i}}^{\Pi+}$, then the $R^{\Pi}$ level is decreasing according to the function $R_{M_{i}}^{\Pi-}$.

Knowing functions $R_{M_{i}}^{\Pi+}, R_{M_{i}}^{\Pi-}$ for each training activity $M_{i}$, and the length of the activity $t_{M_{i}}^{\Pi}$, we can define the best starting moment $t_{M_{i}}^{0}$ for each $M_{i}$ activity so, that $R_{\min }^{\Pi} \leq R^{\Pi} \leq R_{\max }^{\Pi}$, or, at least, $R_{\min }^{\Pi} \leq R^{\Pi}$.

While compiling the training plan (syllabus) for technological process automation experts, it is necessary to calculate level $R_{M_{i}}^{\Pi}$ for each $M_{i}$ activity, taking into account the earlier performed activities, which form its formation base and directly influence the efficiency of its performing (see 9 - 10). 


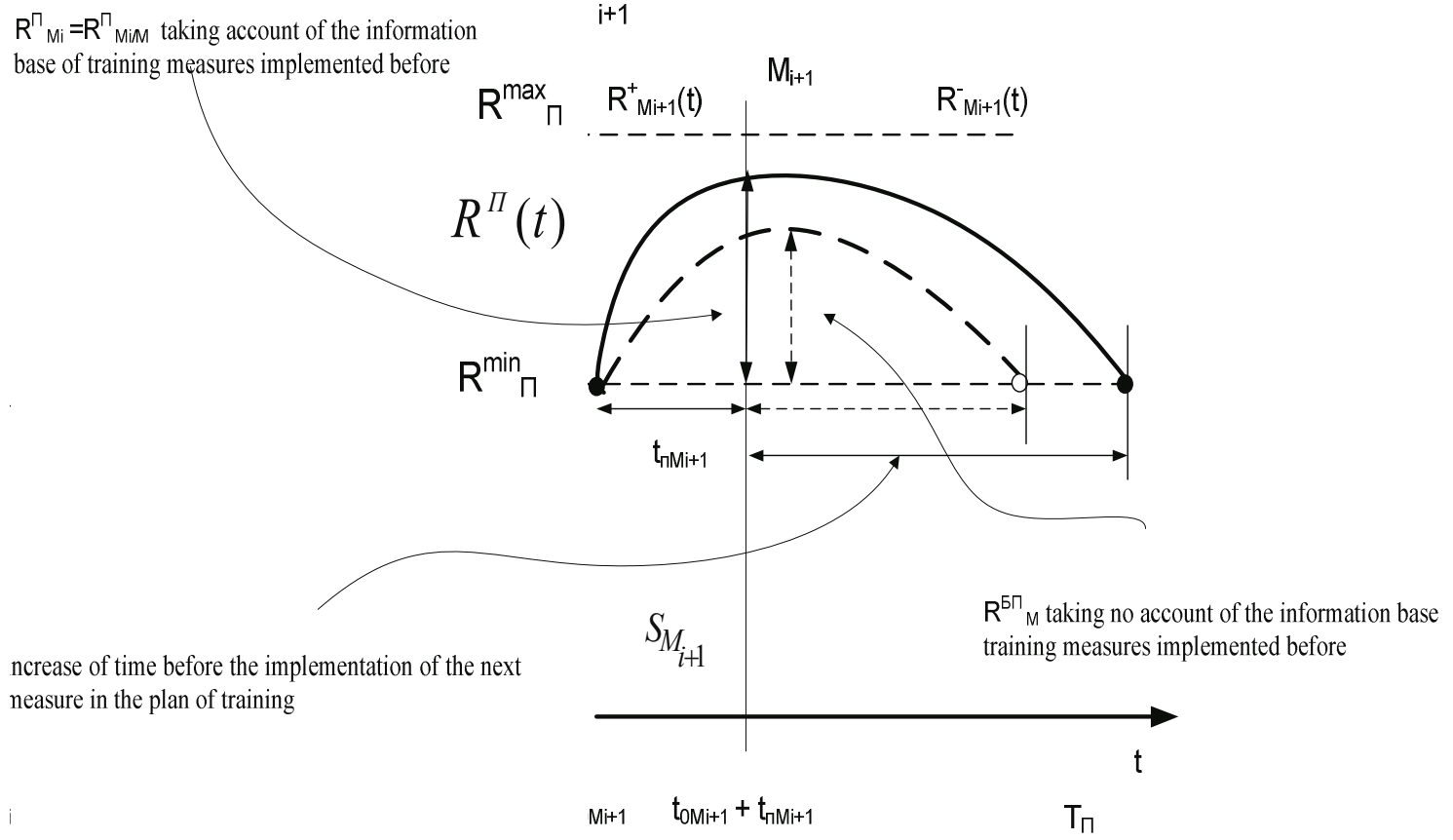

Fig. 7. Calculation of for preparing $M_{i}$ activity, taking into account the information base of the earlier performed activities

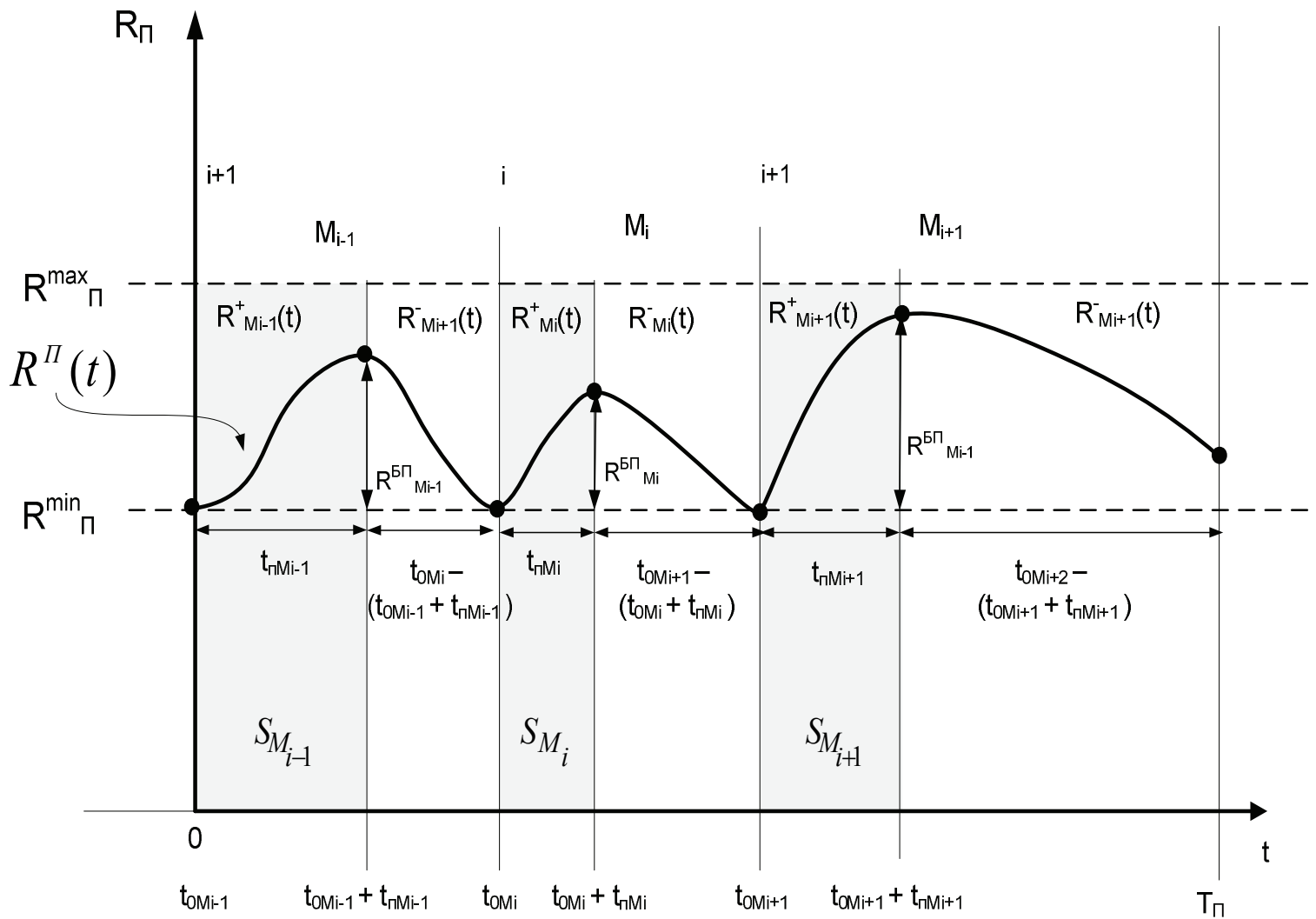

Fig. 8. Process of planning training of the numeric control machines operators, taking into account the parameters of activities being performed

It permits raising the training quality level of the numeric control machines operators without raising expenses on performing each $M_{i}$ 
training activity, as well as the training plan (syllabus) for the technological processes automation experts as a whole.

It is obvious, that level $R_{M_{i} / M}^{\Pi}$ of training activity $M_{i}$, with account of the information base, obtained from the earlier performed activities, which extends the time period before the next activity performing according to the training syllabus. That is, while planning, $R_{M_{i}}^{\Pi}$ should be calculated as $R_{M_{i} / M}^{\Pi}$.

Conclusions of the present study and prospects of further development in this field. The main condition of compiling the syllabus for training the technological processes automation experts is the requirement, that the training quality level of each activity must be calculated with account of the earlier performed activities, which create its information base and directly influence the efficiency of its performance.

The given condition permits raising the training quality level of the numeric control machines operators without raising expenses on performing each training activity and on the plan (syllabus) of training the technological processes automation experts as a whole.

Application of the described model will permit providing of the training process objects qualification level, permitting them to utilize the capabilities of the technological processes equipment to the fullest possible extent.

\section{References}

1. Borodin, I. F., Andreyev, S. A. (2006). Technological processes automation and automatic control systems. Kiev: KolosS, 352 p.

2. Berestnyeva, O. G., Muratova, Ye. A. (2010). Computer analysis of the data. Tomsk: Publishing house of Tomsk State Pedagogical University, $304 \mathrm{p}$.

3. Marukhin, O. V., Shevelyov, G. Ye. (2009). Using the results of the expert assessment to measure the competence of students and graduates of technical universities. Proceedings of the TPU, vol. 315, no. 5, pp.199-203.

4. Vdovin, V. M., Surkova, Lye, Valentinov, V. A. (2013). Systems theory and the systemic analysis: Manual for undergraduates, Moscow: Dashkov i Co., 644 p.

5. Kirillov, V. I. (2013). Qualimetry and the systemic analysis: Study guide. Moscow: SIC INFRA-M, Novoye Znaniye, $440 \mathrm{p}$.

6. Boyko, E. E. (2010). HR record management computerizing. Moscow: Upravlieniye Personalom, 136 p. 